\title{
"Staying Behind and Looking Forward: Characteristics of Urban Afghan Youth with No Intent to Seek Asylum"
}

\author{
Qais Alemi ${ }^{1, *}$, Valerie Smith ${ }^{2}$ and Susanne Montgomery ${ }^{1}$ \\ 1 Department of Social Work \& Social Ecology, School of Behavioral Health, Loma Linda University, \\ 1898 Business Center Drive, San Bernardino, CA 92408, USA; smontgomery@1lu.edu \\ 2 Department of Health Sciences, California State University, East Bay, 25800 Carlos Bee Blvd., \\ Hayward, CA 94542, USA; valeriejs2@gmail.com \\ * Correspondence: qalemi@llu.edu; Tel.: +1-909-379-7592
}

\begin{abstract}
Insecurity, corruption, and rising unemployment have resulted in a mass exodus of young adult Afghans seeking asylum in western nations. This has depleted Afghanistan of generations of young people which are critical to rebuild the country. This study aimed to examine the characteristics of young adult Afghans with no immediate intentions of seeking international asylum; that is, individuals who intend to stay in Afghanistan. In a cross-sectional study conducted in Kabul, we surveyed 232 young adults between 18 and 35 years of age. Surveys included measures assessing standard socio-demographic and -economic factors, as well as health and psychological factors. Univariate logistic regression analyses suggest that participants with an intent to stay in Afghanistan are more likely to be financially stable, possess higher health-related quality of life, lower psychological distress, and higher levels of hope and optimism, as well as higher resilience. When controlling for all other variables in the model, only hope, optimism, and higher resilience remained as significant correlates of intending to stay. Our findings suggest that young people who intend to stay in their country look forward to a better future, which provides strong evidence for the need to strengthen the social contract by fostering resilience, hope and optimism in war-affected communities, in order to prevent a generation of talented young people from seeking asylum in western nations.
\end{abstract}

Keywords: Afghanistan; health; hope; resilience; young people 


\section{INTRODUCTION}

Afghanistan has endured nearly four decades of political violence, which has taken a toll on its institutions and its way of life [1](UNDP, 2016). Despite the international community's efforts to secure peace and improve economic conditions after 9/11, Afghanistan's living conditions remain among the poorest in the world, a predicament exacerbated by problems related to criminality, weak governance, and lack of infrastructure [2]. Indeed, the most recent Asia Foundation [3] survey conducted in Afghanistan, polling over 12,000 people in 34 provinces finds that Afghans are more pessimistic than ever before due to insecurity, corruption, rising unemployment, and slow job growth. With the withdrawal of international forces, Afghans now live with a greater sense of uncertainty, and many seek international asylum to cope with these challenges [4].

Our recent study of undocumented Afghan migrants in Istanbul, a major transit hub for Afghans seeking asylum in European Union (E.U.) member states, shows that a combination of 'push and pull' factors have prompted many young, educated men, from urban areas in Afghanistan to leave their homes and make the perilous journey abroad [5]. Push factors include non-favorable social, economic, political occurrences in Afghanistan, while pull factors include the promise of economic prosperity in the E.U. This is evidenced by the unprecedented number of new Afghan asylum claims made in E.U. member states in 2016 [6]. Many fear that the exodus of Afghans will continue given the worsening security situation, rampant socio-economic inequalities, and a burgeoning working age population of young adults over 18 who make up $63 \%$ of the general population, and who have little opportunity for decent employment [7].

With the expansion of higher education in developing countries, unprecedented numbers of university graduates form a growing group that according to Urdal [8]- pose a security risk for 
countries with labor markets unable to accommodate this surplus, leading to frustration and grievances that could motivate political violence like terrorism, riots and violent demonstrations. The Arab Spring provides stark anecdotal evidence of this [9], and aligns with Stewart's [10] argument for social contract theory suggesting violence is inevitable when states are unable to provide reasonable economic conditions.

Anecdotal evidence suggests that Afghanistan is headed down this path with young people pushed into drug trafficking or joining the insurgency, solely to earn an income [11] or others giving up and deciding to leave the country in search of better opportunities. Many educated, urban youth are disillusioned and distressed as a result limited opportunities for social advancement and upward mobility [12], a consequence of a broken economy and a culture of pervasive nepotism instituted by those in positions of power [13]. Maley [14] contends that changing this situation and challenging the elites currently in positions of power can only occur by engaging with young people who remain committed to building a better future for themselves and their country.

Gaining a deeper understanding of the reasons why some young Afghans choose to remain and rebuild Afghanistan, despite a worsening security situation and economic misery, is important to keeping the country vibrant. As part of a larger cross-sectional health study conducted in Kabul, this paper examines the demographic, health, and psychological characteristics of young adults who made the decision to stay in the country and are committed to rebuilding Afghanistan. We argue that gaining a better understanding of who the individuals are who are committed to staying (demographic, health, and psychological) and how they view their lives and future, will help us inform approaches toward rebuilding and stabilizing the country. These approaches should aim to foster opportunities and resilience in Afghanistan's 
war-affected communities [15], to prevent a generation of talented young people from seeking asylum in European nations where austere economies and anti-immigrant/Muslim sentiments offer little hope for economic prosperity and safe asylum [16].

\section{MATERIALS \& METHODS}

\section{Participants and Procedures}

Inclusion criteria for this study were being an adult between the ages of 18 and 35 and currently residing in Kabul, Afghanistan. As part of a larger cross-sectional study conducted in late 2015, participants were recruited across various districts in Kabul using a combination of convenience, snowball, and street-intercept techniques. Two Afghan research assistants recruited participants using an information sheet that provided details about the study, their rights, and the survey. The ethical merits of this study were approved by the affiliated university Institutional Review Board (IRB), and locally by the Ministry of Public Health in Afghanistan.

\section{Measures}

\section{Dependent Variable}

In order to determine participants' inclinations towards leaving or staying in Afghanistan, we used a single item measure asking participants "Do you plan on leaving Afghanistan to seek refuge elsewhere in the near future?” with a binary 'yes-no' response choice. Our dependent variable is henceforth referred to as intent to stay.

\section{Independent Variables}

Socio-demographic Factors. Standard questions were used to assess age (continuous), gender, ethnicity (e.g. Pashtun, Tajik, etc.), marital status, education (both in years completed and highest attained ranging from 'less than high school' to a 'university degree'), employment, and income (for brevity we asked individuals whether their current income was adequate to meet 
their monthly household financial needs with a 'yes-no' response choice).

Health-Related Factors. The physical and mental health components of the ShortForm $/ S F-8$ [17] were used to provide a measure of health-related quality of life (HR-QoL). The choice of this measure was partly based on Roberts' et al. [18] validation study demonstrating the utility of the SF-8 as a brief measure of physical and mental health with conflict-affected populations in Northern Uganda. Four items on the physical health component related to physical functioning, role limitations (due to physical health problems), bodily pain, and perceived general health. The mental health component contains four items relating to vitality, social functioning, role limitations (owing to emotional problems), and mental health (extent of emotional problems such as anxiety, depression, or irritability). Items are based on a four-week recall period with each item consisting of a five or six-point response choice. A norm based scoring procedure is used in order to generate Physical (PCS) and Mental (MCS) Component Summary scores as indicated in the instrument's guidelines [19]. Higher PCS and MCS scores indicate better physical and mental health status. Both subscales demonstrated acceptable to low scale reliability (PCS: Cronbach's $\alpha=0.70$; MCS: Cronbach's $\alpha=0.66$ ). Additionally, we established convergent validity as individual items in the PCS and MCS were moderately correlated with their respective component summary measures (PCS item range: Pearson's $r=$ 0.59-0.76; MCS item range: Pearson's $r=0.33-0.53)$.

We also measured psychological distress symptoms using a culturally-grounded measure of mental health developed in Afghanistan-the Afghan Symptom Checklist (ASCL) [20]. Items are based on a two-week recall period and are rated on a scale ranging from 1 ("never") to 5 (“everyday"). Scores range from 23 to 115 with higher scores indicative of higher levels of distress. The ASCL demonstrated excellent reliability in this sample (Cronbach's $\propto=.914$ ). 
Psychological Factors. For brevity, we assessed perceived hope using a single-item measure asking participants whether they believed that 'young people would have a better future in Afghanistan as compared to their parents' with a binary 'yes-no' response choice. Similarly, we measured perceived optimism using single item measure asking participants if they were 'optimistic in terms of Afghanistan's future,' also with binary 'yes-no' response choice. We also used the Connor-Davidson Resilience Scale-10 (CD-RISC-10), an abridged version of the 25item CD-RISC, to measure resilience, which according to developers of the original scale is defined as 'one's ability to thrive in the face of adversity' [21]. The 10-item version of the CDRISC [22] includes items that reflect the ability to tolerate experiences such as change, personal problems, illness, pressure, failure, and painful feelings. Items are based on a one-month recall period and are rated on a scale of 0 ("not true at all") to 4 ("true nearly all the time"). Scores range from 0-40 with higher scores indicative of higher resilience. The CD-RISC-10 demonstrated adequate reliability in this sample (Cronbach's $\propto=.765$ ).

\section{Data Analysis}

SPSS, version 24.0 [23] was used for all data analysis. For scales missing less than $10 \%$ responses we used the mean substitution method [24] to handle missing data. Throughout our analyses we examined demographic, health, and psychological differences between individuals who intended to stay versus those who intended to leave Afghanistan using chi-square tests of independence and independent samples t-tests as appropriate. For model building purposes we identified variables significantly related to the dependent variable at $\mathrm{p}<.10$ using univariate logistic regression by generating unadjusted odds ratios (ORs), 95\% confidence intervals, and pvalues. Candidate variables were subsequently entered into a multivariate logistic regression model exploring those more likely to stay, producing adjusted ORs, 95\% CIs, and p-values. 
Statistical significance was considered at $\mathrm{p}<.05$. All models were screened for multicollinearity through an examination of tolerance statistics for predictor variables. Tolerance was found to be greater than .1 for all variables, indicating that multicollinearity is not a problem. Linearity of the logit was ascertained by ensuring that $\mathrm{p}$-values for Hosmer and Lemeshow tests for each model exceeded .05 , which we confirmed.

\section{RESULTS}

\section{Descriptive Analysis}

Table 1 describes variables for the 232 participants who completed the survey comparing those who intend to stay $(n=146)$ with those who are considering leaving Afghanistan in the near future $(\mathrm{n}=86)$. Participants in both groups were similar for many variables. They were on average $23.29( \pm 4.59)$ years of age, male $(56.8 \%)$, unmarried $(62.3 \%)$, of Pashtun ethnicity (36.8\%), unemployed (57.7\%). We found significant differences between the two groups, with those more likely to stay reporting more comfortable incomes (41.7\% vs. $27.9 \%)$, being more optimistic about the socio-political future of the country ( $81.1 \%$ vs $35.3 \%)$, being more hopeful (34.5\% vs. $72.9 \%$ ), more resilient (20.28 vs 23.10$)$, presenting with higher physical (45.06 vs. 47.61) and mental health (39.96 vs. 45.50) status (HR-QoL), as well as lower reported distress symptoms (53.57 vs. 44.13). 
Table 1

Descriptive Statistics $(N=\mathbf{2 3 2})$

\begin{tabular}{|c|c|c|c|c|}
\hline Variables & $\begin{array}{c}\text { Intent to Leave } \\
\quad(n=86)\end{array}$ & $\begin{array}{c}\text { Intent to Stay } \\
(n=146)\end{array}$ & $\begin{array}{c}\text { Total } \\
(N=\mathbf{2 3 2})\end{array}$ & P-value \\
\hline Age $(\mathrm{m}, \mathrm{SD})$ & $23.36(4.73)$ & $23.37(4.49)$ & $23.29(4.59)$ & n.s. \\
\hline \multicolumn{5}{|l|}{ Gender $(\%)$} \\
\hline Female & 43.2 & 46.5 & 43.2 & \multirow[b]{2}{*}{ n.s. } \\
\hline Male & 56.8 & 53.5 & 56.8 & \\
\hline \multicolumn{5}{|l|}{ Ethnicity (\%) } \\
\hline Pashtun & 44.2 & 32.4 & 36.8 & \multirow{3}{*}{ n.s } \\
\hline Tajik & 31.4 & 38.6 & 35.9 & \\
\hline Other (Hazara, Nuristani, Uzbek) & 24.4 & 29 & 27.3 & \\
\hline \multicolumn{5}{|l|}{ Marital Status (\%) } \\
\hline Married & 37.3 & 39.6 & 38.7 & \multirow{2}{*}{ n.s. } \\
\hline Not Married $^{\mathrm{a}}$ & 62.7 & 60.4 & 62.3 & \\
\hline \multicolumn{5}{|l|}{ Education (\%) } \\
\hline College and beyond & 43 & 38.6 & 40.3 & \multirow{2}{*}{ n.s. } \\
\hline HS Diploma and lower & 57 & 61.4 & 59.7 & \\
\hline \multicolumn{5}{|l|}{ Employment (\%) } \\
\hline Employed & 45.9 & 40.1 & 42.3 & \multirow[b]{2}{*}{ n.s. } \\
\hline Unemployed & 54.1 & 59.9 & 57.7 & \\
\hline \multicolumn{5}{|l|}{ Income $(\%)$} \\
\hline Comfortable & 27.9 & 41.7 & 36.4 & \multirow{2}{*}{$\chi^{2}(1)=4.381, p<.05$} \\
\hline Not comfortable & 72.1 & 58.3 & 63.6 & \\
\hline \multicolumn{5}{|l|}{ Perceived Optimism (\%) } \\
\hline Optimistic & 35.3 & 81.1 & 64 & \multirow{2}{*}{$\chi^{2}(1)=48.610, p<.001$} \\
\hline Not Optimistic & 64.7 & 18.9 & 36 & \\
\hline \multicolumn{5}{|l|}{ Perceived Hope $(\%)$} \\
\hline Hopeful & 34.5 & 72.9 & 58.8 & \multirow{2}{*}{$\chi^{2}(1)=32.273, p<.001$} \\
\hline Not hopeful & 65.5 & 27.1 & 41.2 & \\
\hline CD-RISC-10: Resilience (m, SD) & $20.28(7.24)$ & $23.10(7.27)$ & $21.92(7.41)$ & $t(206)=2.771, p<.01$ \\
\hline \multicolumn{5}{|l|}{ SF-8: Quality of Life } \\
\hline Physical Component Scale/PCS (m, SD) & $45.06(8.58)$ & $47.61(7.02)$ & $49.59(7.77)$ & $t(150)=2.315, p<.05$ \\
\hline Mental Component Scale/MCS (m, SD) & $39.96(10.95)$ & $45.50(8.27)$ & $42.48(10.29)$ & $t(141)=4.031, p<.001$ \\
\hline ASCL: Psychological Distress (m, SD) & $53.57(17.60)$ & $44.13(13.90)$ & $47.40(15.86)$ & $t(130)=-4.036, p<.001$ \\
\hline
\end{tabular}

\section{Multivariate Analysis: Factors Associated with the 'Intent to Stay'}

Severable variables were univariately associated with a respondent's intent to stay, including income $(\mathrm{OR}=1.850, \mathrm{p}<.05)$, perceived hope $(\mathrm{OR}=5.106, \mathrm{p}<.001)$, perceived optimism $(\mathrm{OR}=7.877, \mathrm{p}<.001)$ higher resilience $(\mathrm{OR}=1.056, \mathrm{p}<.05)$, higher physical HQoL $(\mathrm{OR}=1.044, \mathrm{p}<.05)$ mental HQoL $(\mathrm{OR}=1.063, \mathrm{p}<.001)$, and lower distress symptoms $(\mathrm{OR}=$ $.963, \mathrm{p}<.001)$. Notably there were no gender differences. After controlling for all variables in the model, (adjusted) ORs for perceived hope and perceived optimism decreased to 2.521 and 4.554, respectively, but their relationships with the dependent variable remained significant as 
did the OR for resilience, which in fact slightly increased from 1.056 to 1.070 . Income was no longer significantly associated with the dependent variable although gender began to approach significance $(\mathrm{p}=.07)$, with females more than twice as likely to indicate their intent to stay in Afghanistan $(\mathrm{OR}=2.077, \mathrm{CI}=.963-4.479)$. In summary, perceived hope, perceived optimism, and resilience were significantly associated with the intent to stay in Afghanistan.

\section{[Insert Table 2 about here]}

Table 2.

Logistic regression analysis predicting 'intent to stay' in Afghanistan

\begin{tabular}{|c|c|c|c|c|}
\hline \multirow{2}{*}{$\frac{\text { Variables }}{\text { Gender }}$} & \multicolumn{2}{|c|}{$\begin{array}{c}\text { Univariate } \\
\text { ORs [CI 95\%] }\end{array}$} & \multicolumn{2}{|c|}{$\begin{array}{l}\text { Multivariate }^{a} \\
\text { ORs [CI 95\%] }\end{array}$} \\
\hline & 1.441 & {$[.834-2.492]$} & $2.077^{\dagger}$ & {$[.963-4.479]$} \\
\hline Income & $1.850^{*}$ & {$[1.036-3.302]$} & 1.063 & {$[1.056-6.022]$} \\
\hline Perceived Hope & $5.106 * * *$ & {$[2.856-9.127]$} & $2.521 *$ & {$[1.950-10.633]$} \\
\hline Perceived Optimism & $7.877 * * *$ & {$[4.276-14.510]$} & $4.554 * * *$ & [1.950-10.633] \\
\hline Resilience & $1.056 * *$ & {$[1.015-1.099]$} & $1.070 *$ & {$[1.015-1.128]$} \\
\hline Physical HR-QoL & $1.044 *$ & {$[1.008-1.082]$} & 1.001 & {$[.949-1.055]$} \\
\hline Mental HR-QoL & $1.063 * * *$ & {$[1.032-1.095$} & 1.019 & {$[.972-1.068]$} \\
\hline Psychological Distress Symptoms & $.963 * * *$ & {$[.945-.981]$} & .978 & {$[.949-1.008]$} \\
\hline
\end{tabular}

\section{DISCUSSION}

Decades of political violence coupled with a broken economy have left citizens of Afghanistan with few options. According to Matsumoto [25], either 'exit or violence' are alternative strategies that are increasingly defining Afghanistan's political transition. However, the results of our study reminds us that an important third option remains, namely individuals intending to stay in Afghanistan wanting to make things work for their country, which of note, involved the majority of our participants $(63 \%)$. These individuals are characterized by them managing to maintain a hopeful, optimistic, and resilient outlook on life despite the current challenges. Tapping into these characteristics and supporting these individuals to maintain such 
positive attitudes should be a key focus in stabilizing Afghanistan and stemming the flood of immigrants fleeing the country.

Strikingly, a sizable sample of people in this study decided to stay because they thought that they would have a "better future in Afghanistan as compared to their parents" (hope) and were optimistic “in terms of Afghanistan's future.” While female gender in our multivariate analyses emerged somewhat, surprisingly, relative economic prosperity, and HR-QoL were no longer central to predicting the intent to stay when all potential factors were controlled for. Considering the current migration trends and the economically insecure and politically volatile urban setting of Kabul where our data was collected, the lack of centrality of gender (we expected that men would be more likely to leave) and socio-economic variables was unexpected especially as in Kabul perceived social disadvantages are pervasive [12].

Nor surprisingly but still important to note, participants intending to stay were also more resilient, in terms of a measure designed to test 'one's ability to thrive in the face of adversity' [22]. These individuals may enjoy the protection of stronger social environments such as family and community ties [26], giving them the capacity to navigate their way to, and collectively negotiate for socio-cultural, -psychological, and physical resources that help them sustain their well-being [27]. Aligned with our findings, Trani et al. [28] found in another study conducted in Afghanistan, that subjective well-being was not dependent on shelter or relative wealth, but rather values of sharing love and care and in other ways taking part in their communities. Similarly, Biswa-Diener and Diener [29] found that slum dwellers in Calcutta, even though they lived in extremely impoverished conditions, reported positive subjective well-being, especially when they were able to experience social relationships they found rewarding. 
Future research should focus on unpacking the concept of individual resilience in the context of Afghanistan, which is especially important given the pervasively dysfunctional economy that would be difficult to base their hope and optimism on their prospects, alone or even on higher education which at this point gives little return on investment. Because resilience and fortitude rest upon a sense of hope (the belief that adversity can be overcome), which is rooted in long lived cultural values congruent within Afghan society, such as faith, individual effort and family unity), interventions should strengthen these innate assets related to resilience [30]. Thus, solidifying and rebuilding existing cultural assets seems to be both a concrete and promising approach which would likely result in increasing hope for the future, making residents less likely to want to leave the country, especially as options abroad are increasingly dim.

While more research is needed to identify the specific influences and cultural values that are associated with these more positive attitudes, our findings speak to the critical need to embrace the growing generation of young people to assure a positive socio-political future in Afghanistan [14]. This is not a new concept. In his analysis of African nations, Mabala [31] suggests that national governments, donor agencies and NGOs should prioritize their resources to improve the livelihoods of young people through positive and meaningful engagement, for example, by institutionalizing a youth perspective. This likely will require a more inclusive political approach that engages individuals commonly marginalized, such as women [15], a subgroup for which our data indicates may be more likely to stay as compared to their male counterparts (this relationship approached significance). Women have described as being instrumental during and after wars in providing a sense of family and community continuity that supports healing from war-related trauma for younger generations [32]. 
Another approach would be to build on the highly educated young male workforce and increase their political participation, which has been linked with better resilience, which in turn has been shown to moderating the link between war exposure and poor mental health [33]. Political participation, including encouraging individuals to engage in social, cultural, and recreational events may also increase resilience via increasing a sense of community, which has been described as crucial to improving quality of life among young people [34]. While this may be viewed as idealistic in an Afghan context of corruption, nepotism, and criminality that have grown out of control, we hope that this study will prompt policy makers and researchers alike to invest in pursuing this in Afghanistan's future.

Limitations to this study exist. The cross-sectional design does not allow for making causal inferences, and the fact that our sample was limited to urban young adults, suggests that our results may not be generalizable throughout Afghanistan. Also, we used a measure assessing individual resilience, which despite displaying good reliability and undergoing a rigorous translation process, may have little content validity in a collectivistic Afghan society. This however would likely lead to an underestimate of the important of resilience. Also, given the sensitive nature of asking about financial issues, we measured income using a single item question regarding the person's ability to meet household financial needs. A more in-depth measures assessing material wealth [12] would have been ideal and we are not sure how it may have influenced our findings. However, given the current challenges of a functioning official economy the decision to ask if people could meet their needs seemed more prudent than asking questions that may have challenged our respondent's ability to be forthcoming. 


\section{Conclusions}

Our research has highlighted that young adult Afghans do indeed look forward to a better future in their country, underscoring the need to reinstate a social contract that prioritizes the needs of young people and promotes security, social advancement and inclusion, and overall well-being. Mitigating the effects of social stressors on the health and well-being of young Afghans is in many ways critical to Afghanistan's future, and as suggested could prevent a much needed generation of young people from exiting Afghanistan. 


\section{References}

1. United Nations Development Programme. About Afghanistan. http://www.af.undp.org/content/afghanistan/en/home/countryinfo/

2. Central Intelligence Agency. South Asia: Afghanistan. https://www.cia.gov/library/publications/the-world-factbook/geos/af.html [accessed 12 February 2017].

3. The Asia Foundation. Afghanistan in 2016. A survey of the Afghan people. http://asiafoundation.org/where-we-work/afghanistan/survey/ [accessed 12 February 2017].

4. Petrillo ER (2016). The Securitization of the EU External Borders and the Rise of Human Smuggling along the Eastern Mediterranean Route. Migration in the Mediterranean: Socio-economic Perspectives, 105; 2016.

5. Author et al. Out of the frying pan, into Istanbul: exploring narratives of trauma, and stressful living difficulties among Afghan migrants. Manuscript submitted for publication, 2016.

6. Eurostat. Asylum statistics.

http://ec.europa.eu/eurostat/statisticsexplained/index.php/Asylum_statistics\#Main_statisti cal_findings [accessed 12 February 2017].

7. United Nations Population Fund. Young People. http://afghanistan.unfpa.org/topics/young-people-0 [accessed 12 February 2017].

8. Urdal H. A clash of generations? Youth bulges and political violence. International Studies Quarterly 2006;50(3):607-29.

9. Hamann, G. (2011). Towards a New Social Contract: Social Justice in North Africa and Middle East. Friedrich-Ebert-Stiftung (September). Retrieved from library.fes.de/pdffiles/iez/08475.pdf [accessed 12 February 2017].

10. Stewart F, Holdstock D, Jarquin A. Root causes of violent conflict in developing countries/Commentary. British Medical Journal 2002;324(7333):342-45.

11. Lavender L. The youth bulge in Afghanistan: Challenges and Opportunities. Civil Military Fusion Centre. http://www.operationspaix.net/DATA/DOCUMENT/6394 v The_Youth_Bulge_in_Afg hanistan_Challenges_and_Opportunities.pdf [accessed 12 February 2017].

12. Panter-Brick C, Eggerman M, Mojadidi A, McDade TW. Social stressors, mental health, and physiological stress in an urban elite of young Afghans in Kabul. American Journal of Human Biology 2008;20(6):627-41. 
13. Transparency International. (2016). National integrity system assessment Afghanistan 2015. https://www.transparency.org/whatwedo/publication/afghanistan_2015_national_integrit y_system_assessment [accessed 12 February 2017].

14. Maley W. Challenges of Political Development in Afghanistan: Mass, Elite and Institutional Dimensions. International Studies 2011;48(1):21-41.

15. United Nations Development Programme. Engaged societies, responsive states: the social contract in situations of conflict and fragility.

http://www.undp.org/content/dam/undp/library/Democratic\%20Governance/Social_Contr act_in_Situations_of_Conflict_and_Fragility.pdf?download [accessed 12 February 2017].

16. Bansak K, Hainmueller J, Hangartner D. How economic, humanitarian, and religious concerns shape European attitudes toward asylum seekers. Science 2016;354(6309):21722 .

17. Ware JE, Kosinski M, Dewey JE, Gandek B. How to Score and Interpret Single-Item Health Status Measures: A Manual for Users of the SF-8 Health Survey. Lincoln, RI: QualityMetric Incorporated; 2001.

18. Roberts B, Browne J, Ocaka KF, Oyok T, Sondorp E. The reliability and validity of the SF-8 with a conflict-affected population in northern Uganda. Health and Quality of Life Outcomes 2008;6(1):108.

19. Maruish ME, DeRosa MA. A Guide to the Integration of Certified Short Form Survey Scoring and Data Quality Evaluation Capabilities. Lincoln, RI: QualityMetric Incorporated; 2009.

20. Miller KE, Omidian P, Quraishy AS et al. The Afghan symptom checklist: a culturally grounded approach to mental health assessment in a conflict zone. American Journal of Orthopsychiatry 2006;76(4):423-33.

21. Connor KM, Davidson JR, Development of a new resilience scale: The Connor-Davidson resilience scale (CD-RISC). Depression and Anxiety 2003;18(2):76-82.

22. Campbell-Sills L, Stein MB. Psychometric analysis and refinement of the ConnorDavidson Resilience Scale (CD-RISC): validation of a 10-item measure of resilience. Journal of Traumatic Stress 2007;20:1019-28.

23. IBM Corp. Released 2013. IBM SPSS Statistics for Macintosh Version 24.0. Armonk, NY: IBM Corp; 2016.

24. Cohen, J., Cohen, P., West, S. G., \& Aiken, L. S. (2013). Applied multiple regression/correlation analysis for the behavioral sciences. Mahwah, NJ: Routledge; 2013. 
25. Matsumoto Y. Young Afghans in 'transition': towards Afghanisation, exit or violence?. Conflict, Security \& Development 2011;11(5):555-78.

26. Betancourt TS, Khan KT. (2008). The mental health of children affected by armed conflict: protective processes and pathways to resilience. International Review of Psychiatry 2008;20(3):317-28.

27. Ungar M. The social ecology of resilience: Addressing contextual and cultural ambiguity of a nascent construct. American Journal of Orthopsychiatry 2011;81(1):1-17.

28. Trani JF, Bakhshi P, Rolland C. Capabilities, perception of well-being and development effort: some evidence from Afghanistan. Oxford Development Studies 2011;39(4):40326.

29. Biswas-Diener R, Diener E. Making the best of a bad situation: satisfaction in the slums of Calcutta. Social Indicators Research 2001;55(3):329-52.

30. Eggerman M, Panter-Brick C. (2010). Suffering, hope, and entrapment: Resilience and cultural values in Afghanistan. Social Science \& Medicine 2010;71(1):71-83.

31. Mabala R. Youth and "the hood"-livelihoods and neighbourhoods. Environment and Urbanization 2011;23(1):157-81.

32. McKay S. The effects of armed conflict on girls and women. Peace and Conflict: Journal of Peace Psychology 1998;4(4):381-92.

33. Tol WA, Song S, Jordans MJ. Annual research review: Resilience and mental health in children and adolescents living in areas of armed conflict-a systematic review of findings in low-and middle-income countries. Journal of Child Psychology and Psychiatry 2013;54(4), 445-60.

34. Cicognani E, Pirini C, Keyes $C$ et al. Social participation, sense of community and social well being: a study on American, Italian and Iranian university students. Social Indicators Research 2008;89(1):97-112. 